\title{
Effects of High-Pressure Processing on In Vitro Infectivity of Encephalitozoon cuniculi
}

Author(s): Carly N. Jordan , Anne M. Zajac, Daniel Holliman, George J. Flick, and David S. Lindsay

Source: Journal of Parasitology, 91(6):1487-1488. 2005.

Published By: American Society of Parasitologists

DOI: http://dx.doi.org/10.1645/GE-568R.1

URL: http://www.bioone.org/doi/full/10.1645/GE-568R.1

BioOne (www.bioone.org) is a nonprofit, online aggregation of core research in the biological, ecological, and environmental sciences. BioOne provides a sustainable online platform for over 170 journals and books published by nonprofit societies, associations, museums, institutions, and presses.

Your use of this PDF, the BioOne Web site, and all posted and associated content indicates your acceptance of BioOne's Terms of Use, available at www.bioone.org/page/terms of use.

Usage of BioOne content is strictly limited to personal, educational, and non-commercial use. Commercial inquiries or rights and permissions requests should be directed to the individual publisher as copyright holder. 
American Society of Parasitology. Carly N. Jordan, Anne M. Zajac, Daniel Holliman, George J. Flick, and David S. Lindsay (2005). "Effects of High-Pressure Processing on In Vitro Infectivity of Encephalitozoon cuniculi," Journal of Parasitology, Vol. 91, No. 6, pp. 1487-1488. doi: http://dx.doi.org/10.1645/GE-568R.1

\title{
Effects of High-Pressure Processing on In Vitro Infectivity of Encephalitozoon cuniculi
}

\author{
Carly N. Jordan, Anne M. Zajac, Daniel Holliman*, George J. Flick*, and David S. Lindsay, Center for Molecular Medicine and Infectious \\ Diseases, Department of Biomedical Sciences and Pathobiology, Virginia-Maryland Regional College of Veterinary Medicine, Virginia Tech, \\ 1410 Prices Fork Road, Blacksburg, Virginia 24061-0342; *Department of Food Science and Technology, Virginia Tech, Duck Pond Drive, \\ Blacksburg, Virginia 24061. e-mail: lindsayd@vt.edu
}

\begin{abstract}
High-pressure processing (HPP) has been shown to be an effective means of eliminating bacteria and destructive enzymes from a variety of food products. HPP extends the shelf life of products while maintaining the sensory features of food and beverages. In this study, we examined the effects of HPP on the infectivity of Encephalitozoon cuniculi spores in vitro. Spores were exposed to between 140 and 550 $\mathrm{MPa}$ for $1 \mathrm{~min}$ in a commercial HPP unit. Following treatment, the spores were loaded onto cell culture flasks or were kept for examination by transmission electron microscopy. No effect was observed on the infectivity of spores treated with $140 \mathrm{MPa}$. Spores treated with between 200 and $275 \mathrm{MPa}$ showed reduction in infectivity. Following treatment of $345 \mathrm{MPa}$ or more, spores were unable to infect host cells. No morphologic changes were observed in pressure-treated spores with transmission electron microscopy.
\end{abstract}

Encephalitozoon cuniculi is a small protist parasite in the Microspora. There are over 1,200 species of microsporidia, and the phylum is characterized by a unique organelle, the polar tube, used to infect host cells. Hosts are infected by ingestion or inhalation of spores passed in the urine or feces, or by transplacental transmission in some animals. Infection with E. cuniculi is usually asymptomatic, except in young or immunocompromised hosts. Diarrhea is the most common symptom of infection in immunocompromised individuals, but disseminated infections can occur, causing conjunctivitis, sinusitis, nephritis, and encephalitis (Franzen and Muller, 2001). Microsporidia infection can be fatal in immunocompromised patients. Human and animal infections with $E$. cuniculi were recognized before the AIDS pandemic, but overall awareness of the phylum as important parasites of warm-blooded animals came about only after the advent of a large immunocompromised population.

High-pressure processing (HPP) is used commercially as a nonthermal means of extending the shelf life of foods and beverages by eliminating pathogens and denaturing destructive enzymes (Tewari et al., 1999). It has a number of advantages over traditional thermal processing, including shorter processing time; minimal heat damage problems; no adverse changes from ice phase forms during pressure-shift freezing; minimal modifications to functionality; and preservation of flavor, texture, color, and vitamin C (Tewari et al., 1999).

This study was conducted in response to recent reports discussing the possibility that microsporidia might be present in juice products (Slifko, Smith, and Rose, 2000). A recent report examined water sources in North and Central America for the presence of protozoan parasites (Thurston-Enriquez et al., 2002). The water sources sampled were used for irrigation of various fruit and vegetable crops. Thurston-Enriquez et al. (2002) discovered that DNA from human pathogenic microsporidia was present in all water sources examined. Microsporidia in irrigation water could adhere to the surface of fruits and vegetables. Because spores are extremely resistant to damage, they can remain viable on the produce for several weeks or months, which also suggests that microsporidia could be present in juice products.

Studies have shown that HPP is useful in eliminating bacteria and protozoa from juices without altering taste or appearance. Slifko, Raghubeer, and Rose (2000) examined the effects of HPP on Cryptosporidium parvum oocysts in apple and orange juice. It was determined that $550 \mathrm{MPa}$ for $60 \mathrm{sec}$ decreases the in vitro infectivity of $C$. parvum oocysts. Lindsay et al. (2005) found that exposure of Toxoplasma gondii oocysts to $340 \mathrm{MPa}$ for $60 \mathrm{sec}$ rendered them noninfectious for mice. Another study found that subjecting orange juice to pressures of 400 MPa for $60 \mathrm{sec}$ significantly reduced the viability of Escherichia coli O157:H7, but some organisms were able to survive the treatment (Lin- ton et al., 1999). This study was conducted to determine the effect of HPP on the infectivity of E. cuniculi spores in cell culture.

Encephalitozoon cuniculi (American Type Culture Collection [ATCC] 50502, Manassas, Virginia) spores were harvested from HS68 cell cultures (see below) by removing the supernatant from infected flasks and passing it through a $3-\mu \mathrm{m}$ filter. In trials 1 and 2 , spores were suspended in Hank's balanced salt solution (HBSS). In trial 3, spores were suspended in pasteurized apple cider. Spores were sealed in leakproof bags at a concentration of $20 \times 10^{6} \mathrm{spores} / \mathrm{ml}$. These bags were placed in additional bags containing a $10 \%$ bleach solution to protect against contamination of the processor. The spores were exposed to pressures ranging from 140 to $550 \mathrm{MPa}$ and held at the desired pressure for $1 \mathrm{~min}$. Three trials were conducted for in vitro infectivity studies, and each measurement was made in triplicate.

Human foreskin fibroblast cells (ATCC, Hs68, CRL-1635) were grown to confluence in $25-\mathrm{cm}^{2}$ cell culture flasks. They were grown in RPMI 1640 medium with $10 \%$ fetal bovine serum, $100 \mathrm{U} / \mathrm{ml}$ penicillin, $100 \mu \mathrm{g} / \mathrm{ml}$ streptomycin, and $1 \mathrm{mM}$ sodium pyruvate added. Spore suspension $(1 \mathrm{ml})$ was removed from each bag and loaded into individual flasks of Hs68 cell cultures. The cultures were examined at 30 or 33 days, and each flask was evaluated for percentage of host cells infected.

One additional study was conducted for examination by transmission electron microscopy (TEM). Spores in HBSS were treated with between 480 and $275 \mathrm{MPa}$ for $1 \mathrm{~min}$ and compared with untreated control spores for changes in morphology. After pressure treatment, $1 \mathrm{ml}$ from each bag was removed and centrifuged to pellet the spores. The spores were fixed in $3 \%(\mathrm{v} / \mathrm{v})$ glutaraldehyde in PBS ( $\mathrm{pH}$ 7.4). Spore pellets were postfixed in $1 \%(\mathrm{w} / \mathrm{v})$ osmium tetroxide in $0.1 \mathrm{M}$ phosphate buffer, dehydrated in a series of ethanols, passed through 2 changes of propylene oxide, and embedded in Maraglass 655 resin (Polysciences Inc.,

TABLE I. Infectivity of Encephalitozoon cuniculi spores in cell culture following high-pressure processing.

\begin{tabular}{ccclc}
\hline Trial & Days PE* & $\begin{array}{c}\text { Pressure } \\
(\mathrm{MPa})\end{array}$ & Infective & $\%$ CPE $\dagger$ \\
\hline \multirow{2}{*}{1} & 30 & 0 & Yes & 90 \\
& & 140 & Yes & 90 \\
& 275 & Yes & 10 \\
& 410 & No & 0 \\
& & 550 & No & 0 \\
2 & 0 & Yes & 70 \\
& 33 & 200 & Yes & 30 \\
& & 275 & Yes & 0 \\
& 310 & Yes & 0 \\
& 345 & No & 0 \\
& 380 & No & 0 \\
& & 410 & No & 0 \\
3 & 480 & No & 0 \\
& & 0 & Yes & 50 \\
& 30 & 200 & Yes & 10 \\
& 240 & Yes & 22 \\
& 275 & Yes & 5 \\
& 310 & No & 0 \\
\hline
\end{tabular}

* Days postexposure cytopathic effect was measured.

$\dagger \%$ Cytopathic effect. 


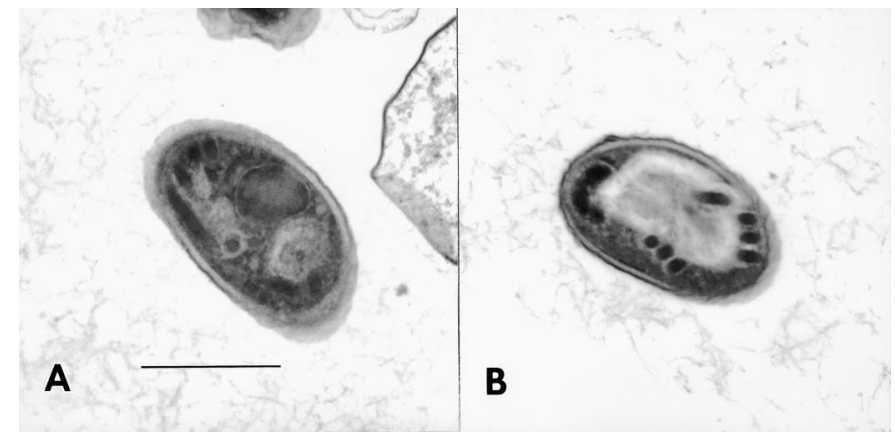

FIGURE 1. Transmission electron micrographs showing the structure of a control spore (A) and a $480 \mathrm{MPa}$ pressure-treated spore (B) of Encephalitozoon cuniculi. Bar $=1 \mu \mathrm{m}$.

Warrington, Pennsylvania). Spores were examined with a Zeiss 10CA transmission electron microscope operating at $60 \mathrm{kV}$, and digital photos were taken with an ATM camera system (Advanced Microscopy Techniques Corp., Danvers, Massachusetts). Seven TEM micrographs were examined from spores treated at $480 \mathrm{MPa}, 21$ from spores treated at $410 \mathrm{MPa}, 12$ from spores treated at $345 \mathrm{MPa}$, and 3 from spores treated at $275 \mathrm{MPa}$. These micrographs were compared with 17 TEM micrographs of untreated E. cuniculi spores.

No effect was observed on the infectivity of spores treated at 140 $\mathrm{MPa}$. Spores treated at pressures between 275 and $310 \mathrm{MPa}$ showed reduction in infectivity, but this result was variable as measured by CPE (Table I). In trial 3, spores were rendered noninfective at $310 \mathrm{MPa}$, whereas in trial 2, a few infected cells were seen, but no CPE was present on day 33 when the host cells were last examined. Following treatment of $345 \mathrm{MPa}$, or more, spores were unable to infect host cells (Table I). Examination by TEM revealed no morphologic changes in the pressure-treated spores compared with controls (Fig. 1).

The results of this study show that pressures of $345 \mathrm{MPa}$ or more render spores of $E$. cuniculi noninfective for cell cultures. Treatment at $310 \mathrm{MPa}$ eliminated infectivity in trial 3, but not in trial 2, indicating that a small number of spores remained viable after treatment at this pressure.

Examination of pressure-treated spores by TEM microscopy did not reveal any morphological changes (Fig. 1). This is not unexpected be- cause HPP acts primarily by disrupting hydrogen bonds and 3-dimensional configuration of protein molecules (Hayakawa et al., 1996).

The study was conducted to examine the possible use of high-pressure processing to sterilize juice products that might contain microsporidia. In at least 1 report, DNA from human pathogenic microsporidia has been found in water sources used for irrigation of produce crops (Thurston-Enriquez et al., 2002). Because microsporidia are resistant to environmental conditions, spores that adhere to produce can still be viable when crops are processed for juice. Some companies are hesitant to pasteurize juice products for fear of weakening the flavor. It is unknown whether pasteurization kills microsporidia, but nonpasteurized products could certainly contain viable spores. High-pressure processing is a viable alternative for producers who do not want to pasteurize juices. Pathogenic bacteria and protozoa can be eliminated, and the processing time required for HPP is shorter.

\section{LITERATURE CITED}

FranZEN, C., AND A. Muller. 2001. Microsporidiosis: Human diseases and diagnosis. Microbes and Infection 3: 389-400.

Hayakawa, I., Y.-Y. LinKo, AND P. LinKo. 1996. Mechanism of high pressure denaturation of proteins. Lebensmittel Wissenschaft und Technologie 29: 756-762.

Lindsay, D. S., M. V. Collins, C. N. Jordan, G. J. Flick, and J. P. DuBEY. 2005. Effects of high pressure processing on infectivity of Toxoplasma gondii oocysts for mice. Journal of Parasitology 91: 699-701.

Linton, M., J. M. McClements, and M. F. Patterson. 1999. Inactivation of Escherichia coli $\mathrm{O} 157: \mathrm{H7}$ in orange juice using a combination of high pressure and mild heat. Journal of Food Protection 62: $277-279$.

SlifKo, T. R., H. V. Smith, And J. B. Rose. 2000. Emerging parasite zoonoses associated with water and food. International Journal for Parasitology 30: 1379-1393.

—, E. RaghUBEeR, AND J. B. Rose. 2000. Effect of high hydrostatic pressure on Cryptosporidium parvum infectivity. Journal of Food Protection 63: 1262-1267.

Tewari, G., D. S. Jayas, and R. A. Holley. 1999. High pressure processing of foods: An overview. Science Des Aliments 19: 619661.

Thurston-Enriquez, J. A., P. Watt, S. E. Dowd, R. Enriquez, I. L. PePPER, AND C. P. GERBA. 2002. Detection of protozoan parasites and microsporidia in irrigation waters used for crop production. Journal of Food Protection 65: 378-382.

\section{Buprenorphine Does Not Affect Acute Murine Toxoplasmosis and is Recommended as an Analgesic in Toxoplasma gondii Studies in Mice}

David S. Lindsay, Taranjit Kaur, Sheila M. Mitchell, David G. Goodwin, Jeannine Strobl`, and J. P. Dubey†, Center for Molecular Medicine and Infectious Diseases, Department of Biomedical Sciences and Pathobiology, Virginia-Maryland Regional College of Veterinary Medicine, Virginia Polytechnic Institute and State University, Blacksburg, Virginia 24061-0342. e-mail: lindsayd@vt.edu; * Biomedical Sciences, Edward Via Virginia College of Osteopathic Medicine, 2265 Kraft Drive, Blacksburg, Virginia 24060; † U.S. Department of Agriculture, Agricultural Research Service, ANRI, Animal Parasitic Diseases Laboratory, BARC-East, Beltsville, Maryland 20705.

ABSTRACT: Groups of mice were infected with tachyzoites of the RH strain of Toxoplasma gondii, treated with the opioid analgesic buprenorphine, sodium sulfadiazine, a combination of buprenorphine and sodium sulfadiazine, or nothing in the drinking water, on days -1 to 12 postinfection. Mice in the $T$. gondii-infected buprenorphine-treated group did not live significantly longer $(P>0.05)$ than mice given $T$. gondii and not treated with buprenorphine. Clinical observations of mice indicated that buprenorphine treatment reduced distress and pain in mice with acute toxoplasmosis. Mice treated with sodium sulfadiazine alone or sodium sulfadiazine combined with buprenorphine survived the 28-day study. Mice treated with buprenorphine and not in- fected with $T$. gondii also survived the 28 days. This study demonstrates that buprenorphine does not adversely interfere with acute $T$. gondii infection and indicates that buprenorphine can be given to mice to alleviate pain and distress associated with a $T$. gondii infection, and not adversely influence the results of toxoplasmosis studies. Analgesic (buprenorphine) treatment should now be the standard of care for mice in acute toxoplasmosis studies.

Buprenorphine is a potent opioid analgesic used to treat moderate to severe pain in humans (Christoph et al., 2005) and as maintenance therapy for opiate addicts (Lutfy et al., 2003). It has a broad analgesic 